\title{
Noncommunicable disease and multimorbidity in young adults with cerebral palsy
}

This article was published in the following Dove Press journal:

Clinical Epidemiology

\section{Daniel G Whitney' \\ Edward A Hurvitz' \\ Jennifer M Ryan ${ }^{2,3}$ \\ Maureen J Devlin ${ }^{4}$ \\ Michelle S Caird ${ }^{5}$ \\ Zachary P French' \\ Elie C Ellenberg' \\ Mark D Peterson'}

'Department of Physical Medicine and Rehabilitation, Michigan Medicine, University of Michigan, Ann Arbor, MI, USA; ${ }^{2}$ Department of Epidemiology and Public Health Medicine, Royal College of Surgeons in Ireland, Dublin, Ireland; ${ }^{3}$ Department of Clinical Sciences, Brunel University London, Uxbridge, UK; ${ }^{4}$ Department of Anthropology, University of Michigan, Ann Arbor, MI, USA; ${ }^{5}$ Department of Orthopedic Surgery, Michigan Medicine, University of Michigan, Ann Arbor, MI, USA
Correspondence: Mark D Peterson Department of Physical Medicine and Rehabilitation, Michigan Medicine, University of Michigan, $325 \mathrm{E}$.

Eisenhower, Suite \#300, Ann Arbor, MI 48I 08, USA

Tel +l 7349367175

Fax +I 7346151770

Email mdpeterz@med.umich.edu
Purpose: Individuals with cerebral palsy $(\mathrm{CP})$ are at increased risk for frailty and chronic disease due to factors experienced throughout the lifespan, such as excessive sedentary behaviors and malnutrition. However, little is known about noncommunicable diseases (NCDs) and multimorbidity profiles in young adults with CP. The study objective was to compare NCD and multimorbidity profiles between young adults with and without $\mathrm{CP}$.

Methods: A clinic-based sample of adults $(18-30$ years) with $(n=452)$ and without $(n=448)$ CP was examined at the University of Michigan Medical Center. The prevalence and predictors of 13 NCDs were evaluated, including existing diagnoses or historical record of musculoskeletal, cardiometabolic, and pulmonary morbidities. The level of motor impairment was determined by the Gross Motor Function Classification System (GMFCS) and stratified by less vs more severe motor impairment (GMFCS I-III vs IV-V). Logistic regression was used to determine the odds of NCD morbidity and multimorbidity in adults with CP compared to adults without CP, and for GMFCS IV-V compared to GMFCS I-III in those with CP, after adjusting for age, sex, body mass index, and smoking.

Results: Adults with CP had a higher prevalence of osteopenia, osteoporosis, hypertension, myocardial infarction, hyperlipidemia, asthma, and multimorbidity compared to adults without $\mathrm{CP}$, and higher odds of musculoskeletal (odds ratio [OR]: 6.97) and cardiometabolic morbidity (OR: 1.98), and multimorbidity (OR: 2.67). Adults with CP with GMFCS levels IV-V had a higher prevalence of osteopenia/osteoporosis, osteoarthritis, hypertension, other cardiovascular conditions, pulmonary embolism, and multimorbidity, and higher odds of musculoskeletal (OR: 3.41), cardiometabolic (OR: 2.05), pulmonary morbidity (OR: 1.42), and multimorbidity (OR: 3.45 ) compared to GMFCS I-III. Conclusion: Young adults with CP have a higher prevalence of chronic NCDs and multimorbidity compared to young adults without $\mathrm{CP}$, which is pronounced in those with more severe motor impairment. These findings reiterate the importance of early screening for prevention of NCDs in CP.

Keywords: cerebral palsy, noncommunicable disease, multimorbidity, osteoporosis, osteoarthritis, cardiovascular disease, diabetes, pulmonary disease

\section{Introduction}

Cerebral palsy $(\mathrm{CP})$ results from damage to or malformation of the infant brain and is the most common physical disability in childhood. ${ }^{1}$ Children with CP present with impaired neuromuscular function, ${ }^{2-4}$ low levels of physical activity, ${ }^{5-7}$ poor cardiorespiratory fitness, ${ }^{8}$ underdeveloped musculoskeletal tissue, ${ }^{5,6}$ and a high degree of fat of total body ${ }^{9}$ and musculoskeletal ${ }^{5,6}$ depots, which are largely governed by the extent of motor impairment. ${ }^{5,6}$ Mobility decrements are common in children with CP as they 
transition into and throughout adulthood. ${ }^{10-12}$ Consequently, individuals with CP may be at a heightened risk for developing chronic, noncommunicable diseases (NCDs) at younger ages compared to the general population.

There has been a considerable shift in the global burden of disease, with the prevalence of NCDs now outranking injuries and communicable, maternal, neonatal, and nutritional disorders combined. ${ }^{13}$ The burden of NCDs has been climbing with estimated costs of $\$ 7$ trillion US dollars by $2030 .{ }^{14}$ The adult CP population is steadily growing due to increases in survival rate ${ }^{15}$ and prevalence ${ }^{16}$ of $\mathrm{CP}$ in recent decades. Indeed, CP represents a significant lifetime disability for individuals, their families, and caregivers. CP is associated with increased prevalence of cardiometabolic mortality ${ }^{17}$ and morbidity, ${ }^{18,19}$ greatly reducing life expectancy, ${ }^{20}$ all of which may develop or be accelerated by the presence of impairments and/or the aging process. ${ }^{18,19}$ There is, thus, strong rationale for approaching health care delivery for persons with CP within the context of a life course health development model. ${ }^{21}$ However, the framework that encompasses clinical care for patients with $\mathrm{CP}$ has been largely confined to issues that arise during childhood and adolescence, with little to no focus on understanding life course health development.

A comprehensive understanding of the primary and resulting sequela associated with aging in those with $\mathrm{CP}$ is lacking, especially in the early adult years. Better understanding these changes in health through the lifespan will help to guide future, target-specific preventive efforts in rehabilitation research and clinical practice to mitigate the exaggerated chronic conditions observed in patients with $\mathrm{CP} .{ }^{19}$ The primary objective of this study was to examine the NCD profiles and risk factors in young adults with CP compared to young adults without CP. We hypothesized that young adults with $\mathrm{CP}$ would have a higher prevalence of NCDs compared to those without CP, and that risk factors would include obesity and greater motor impairments.

\section{Patients and methods}

\section{Patient identification}

A cohort query tool (Data Direct: https://datadirect.med. umich.edu) was used to identify patients who had clinical appointments at the University of Michigan Medical Center, as previously described. ${ }^{19}$ Briefly, we annotated the dataset using the Electronic Medical Records Search Engine (EMERSE) software. The EMERSE software is hosted behind the University of Michigan Medical Center firewall in a computing environment certified for storing protected health information. Access to EMERSE is limited to authorized personnel who have patient data access privileges or, among those using it for research, have provided evidence of training in responsible research practices and proof of valid institutional review board (IRB) approvals, including demonstration of a need to review identifiable patient information. ${ }^{22}$ At each login, users must complete a brief attestation form to document their intent of use. Audit trail logs are kept for each use session. The principal investigators (Peterson and Hurvitz) take full responsibility for de-identifying patient records and maintaining patient data confidentiality. The University of Michigan IRB approved this retrospective study, and patient consent to review their medical record was waived by the IRB because the nature of this study involved no more than minimal risk to the subjects; the waiver did not adversely affect the rights and welfare of the subjects; the research could not practicably (ie, feasibly) be carried out without the waiver.

This internally developed web application provides an interface for searching electronic medical records with a bundle of word iterations and phrases for variables of interest. ${ }^{22}$ Adults between 18 and 30 years of age, with a confirmed diagnosis of CP or no known neurological disorders (controls), who had an encounter with University of Michigan Medicine between 01/01/2011 and 07/31/2017 (6.5-year period), were considered for this study. Among individuals with CP, the distribution of affected limbs (ie, quadriplegic, hemiplegic, diplegic) was obtained from medical records. The level of motor impairment was classified according to the Gross Motor Function Classification System (GMFCS). GMFCS ranks motor impairment with GMFCS I/II reflecting gross motor independence, GMFCS III reflecting the use of assistive walking devices, and GMFCS IV-V reflecting wheelchair use for most to all mobility. We stratified GMFCS into two categories, GMFCS I-III and GMFCS IV-V, to reflect lesser and greater motor impairment, respectively.

\section{Noncommunicable diseases}

Clinical data were included for existing diagnosis or historical record of various NCDs and were grouped into three categories, including 1) musculoskeletal morbidity: osteopenia and osteoporosis, osteoarthritis, and rheumatoid arthritis; 2) cardiometabolic morbidity: stroke, hypertension, other cardiovascular problems (eg, heart valve disorders, peripheral artery disease, aortic aneurysm, heart failure), coronary artery disease, impaired glucose tolerance or type 2 diabetes, myocardial infarction, and hyperlipidemia (total cholesterol $>240 \mathrm{mg} / \mathrm{dL}$ and/or triglyceride $>200 \mathrm{mg} / \mathrm{dL}$ ); and 3 ) pulmonary morbidity: asthma, pulmonary embolism, and emphysema. These conditions were chosen because of their potential impact on physical function and in accordance with the guidance from the literature relating to older adults and adults with disabilities..$^{23,24}$ 
In addition to using the EMERSE, certain variables required additional data collection. For blood pressure, the most recent measurement was used to determine hypertension status (present vs absent) based on the Eighth Joint National Committee: ${ }^{25}$ systolic blood pressure $\geq 140 \mathrm{mmHg}$ and/or diastolic blood pressure $\geq 90 \mathrm{mmHg}$. A clinical history of stroke and/or other cardiovascular problems (eg, heart valve disorders, peripheral artery disease, aortic aneurysm, heart failure) was included if it occurred at 18 years or older. Musculoskeletal, cardiometabolic, and pulmonary morbidities were defined on the basis of presence of at least one of the aforementioned chronic NCDs within each respective category. A morbidity score was created by summing the number of individual NCDs. Multimorbidity was defined as the presence of having at least two of the aforementioned NCDs.

\section{Covariates}

Demographic data, including race, age, and sex, were collected using the EMERSE software. Body mass index (BMI) was calculated by dividing body mass by height squared $\left(\mathrm{kg} / \mathrm{m}^{2}\right)$. BMI was separated into underweight $(<18.5)$, normal weight (18.5-24.9), overweight (25.0-29.9), and obese $(\geq 30.0)$ categories. Smoking status was categorized as never vs current, occasional, or previous smoker.

\section{Statistical analyses}

Descriptive characteristics are provided as mean, standard deviation, and percentages. Participant demographics and NCD prevalence were compared between groups (young adults with vs without $\mathrm{CP}$ ) and between the level of motor impairment for those with CP (GMFCS I-III vs IV-V) using two-sample $t$-tests and chi-square $\left(\chi^{2}\right)$ tests for continuous and categorical measures, respectively. Multiple logistic regression was used to determine the odds of NCD morbidity categories (musculoskeletal, cardiometabolic, and pulmonary) and multimorbidity, after adjusting for age, sex, race, $\mathrm{BMI}$, and smoking status. The primary exposure of $\mathrm{CP}$ was included as a dichotomous indicator variable in all models. Data were analyzed using SAS software version 9.3 (SAS institute, Cary, NC, USA) with 2 -sided $95 \%$ confidence intervals to determine significance.

\section{Results}

\section{Descriptive characteristics}

Descriptive characteristics of the study participants with $(n=452)$ and without $(n=448)$ CP are presented in Table 1.
Table I Descriptive characteristics and NCD prevalence of young adults with and without $C P$

\begin{tabular}{|c|c|c|c|}
\hline & $\begin{array}{l}\text { Without } \\
\text { CP } \\
n=448\end{array}$ & $\begin{array}{l}\text { With } \\
C P \\
n=452\end{array}$ & $p$-value \\
\hline \multicolumn{4}{|l|}{ Descriptive characteristics } \\
\hline Age (years), mean $\pm S D$ & $23.7 \pm 2.8$ & $23.6 \pm 3.4$ & 0.74 \\
\hline Male, $\%$ & 40.0 & 43.4 & 0.23 \\
\hline \multicolumn{4}{|l|}{ Race/ethnicity, \% } \\
\hline Non-Hispanic White & 73.7 & 81.2 & 0.01 \\
\hline Non-Hispanic Black & 7.0 & 11.6 & 0.02 \\
\hline Hispanic or Mexican American & 4.1 & 2.7 & 0.23 \\
\hline Unknown/other race & 15.2 & 4.4 & $<0.001$ \\
\hline \multicolumn{4}{|l|}{ BMI category, \% } \\
\hline Underweight (BMl<18.5) & 0.3 & 24.3 & $<0.001$ \\
\hline Normal weight (BMI I8.5-24.9) & 52.2 & 41.2 & 0.03 \\
\hline Overweight (BMI 25-29.9) & 31.6 & I8. & 0.01 \\
\hline Obese $(\mathrm{BMI} \geq 30)$ & 15.9 & 16.4 & 0.87 \\
\hline Smoking status, \% & 19.3 & 7.1 & $<0.001$ \\
\hline \multicolumn{4}{|c|}{ Chronic NCD and multimorbidity prevalence, \% } \\
\hline Musculoskeletal morbidity & 7.5 & 44.9 & $<0.001$ \\
\hline Osteopenia/osteoporosis & 2.3 & 43.6 & $<0.001$ \\
\hline Osteoarthritis & 4.1 & 5.4 & 0.37 \\
\hline Rheumatoid arthritis & 1.8 & 0.4 & 0.05 \\
\hline Cardiometabolic morbidity & 8.4 & 20.6 & $<0.001$ \\
\hline Stroke & 0.0 & 0.0 & $\mathrm{n} / \mathrm{a}$ \\
\hline Hypertension & 3.2 & 11.8 & $<0.001$ \\
\hline Other heart problems & 4.1 & 5.3 & 0.38 \\
\hline Coronary artery disease & 0.0 & 0.2 & 0.32 \\
\hline Diabetes & 1.4 & 2.2 & 0.33 \\
\hline Myocardial infarction & 0.0 & 2.0 & 0.01 \\
\hline Hyperlipidemia & 1.1 & 3.0 & 0.04 \\
\hline Pulmonary morbidity & 22.2 & 27.9 & 0.04 \\
\hline Asthma & 21.4 & 27.0 & 0.03 \\
\hline Pulmonary embolism & 0.9 & 1.8 & 0.25 \\
\hline Emphysema & 0.0 & 1.0 & 0.05 \\
\hline Multimorbidity & 7.2 & 24.3 & $<0.001$ \\
\hline
\end{tabular}

Abbreviations: BMl, body mass index; CP, cerebral palsy; NCD, noncommunicable disease; $n / a$, not applicable.

There were no group differences in age, sex, or obesity prevalence. However, there were group differences in race, underweight, normal weight, and overweight measures, and adults with $\mathrm{CP}$ had a lower prevalence of smoking status compared to adults without $\mathrm{CP}$.

Of the young adults with CP, 231 (51\%) were classified as GMFCS I-III and 221 (49\%) as GMFCS IV-V (Table 2). There were no group differences in sex or race distribution. However, there were group differences in age, underweight, overweight, smoking status (GMFCS IV-V lower prevalence), and distribution of affected limbs in young adults with CP. A summary of morbidity score prevalence by CP status and GMFCS categories is depicted in Figure 1. 
Table 2 Descriptive characteristics of young adults with cerebral palsy based on motor impairment assessed using the GMFCS

\begin{tabular}{|c|c|c|c|}
\hline & $\begin{array}{l}\text { GMFCS } \\
\text { I-III } \\
n=23 \mid\end{array}$ & $\begin{array}{l}\text { GMFCS } \\
\text { IV-V } \\
n=22 \text { I }\end{array}$ & $\begin{array}{l}\text { Difference } \\
\text { p-value }\end{array}$ \\
\hline \multicolumn{4}{|l|}{ Descriptive characteristics } \\
\hline Age (years), mean $\pm S D$ & $23.0 \pm 3.2$ & $24.3 \pm 3.5$ & 0.01 \\
\hline Male, \% & 39.4 & 47.5 & 0.08 \\
\hline \multicolumn{4}{|l|}{ Race/ethnicity, \% } \\
\hline Non-Hispanic White & 84.4 & 77.9 & 0.09 \\
\hline Non-Hispanic Black & 9.6 & 14.0 & 0.14 \\
\hline Hispanic or Mexican American & 1.7 & 3.6 & 0.21 \\
\hline Unknown/other race & 4.3 & 4.5 & 0.56 \\
\hline \multicolumn{4}{|l|}{ BMI category, \% } \\
\hline Underweight (BMI<18.5) & 10.8 & 38.5 & $<0.001$ \\
\hline Normal weight (BMI & 43.7 & 38.4 & 0.26 \\
\hline \multicolumn{4}{|l|}{$(8.5-24.9)$} \\
\hline Overweight (BMI 25-29.9) & 22.9 & 13.1 & 0.01 \\
\hline Obese $(B M I \geq 30)$ & 22.6 & 10.0 & $<0.001$ \\
\hline Smoking status, \% & 10.4 & 3.8 & 0.01 \\
\hline \multicolumn{4}{|l|}{ Distribution, \% } \\
\hline Quadriplegia & 17.1 & 93.6 & $<0.001$ \\
\hline Hemiplegia & 38.7 & 1.9 & $<0.001$ \\
\hline Diplegia & 44.2 & 4.5 & $<0.001$ \\
\hline \multicolumn{4}{|c|}{ Chronic NCD and multimorbidity prevalence, $\%$} \\
\hline Musculoskeletal morbidity & 31.2 & 59.3 & $<0.001$ \\
\hline Osteopenia/osteoporosis & 29.1 & 58.6 & $<0.001$ \\
\hline Osteoarthritis & 3.1 & 7.7 & 0.02 \\
\hline Rheumatoid arthritis & 0.0 & 0.9 & 0.14 \\
\hline Cardiometabolic morbidity & 15.2 & 26.2 & $<0.01$ \\
\hline Stroke & 0.0 & 0.0 & $\mathrm{n} / \mathrm{a}$ \\
\hline Hypertension & 9.1 & 15.0 & 0.04 \\
\hline Other heart problems & 2.1 & 8.6 & 0.01 \\
\hline Coronary artery disease & 0.0 & 0.5 & 0.31 \\
\hline Diabetes & 1.7 & 2.7 & 0.47 \\
\hline Myocardial infarction & 1.3 & 2.3 & 0.43 \\
\hline Hyperlipidemia & 2.2 & 3.2 & 0.51 \\
\hline Pulmonary morbidity & 25.5 & 30.3 & 0.26 \\
\hline Asthma & 24.8 & 28.6 & 0.36 \\
\hline Pulmonary embolism & 0.4 & 3.5 & 0.02 \\
\hline Emphysema & 0.4 & 0.5 & 0.96 \\
\hline Multimorbidity & 15.2 & 33.9 & $<0.001$ \\
\hline
\end{tabular}

Abbreviations: BMI, body mass index; GMFCS, Gross Motor Function Classification System; NCD, noncommunicable disease.

\section{Musculoskeletal morbidity}

Adults with CP had a higher prevalence of osteopenia/osteoporosis compared to those without CP (Table 1). Adults with CP had a higher odds of musculoskeletal morbidity compared to those without CP (Table 3). Greater age, being underweight, and smoking status were all significantly associated with musculoskeletal morbidity.

Of the adults with CP, those with GMFCS IV-V had a higher prevalence of osteopenia/osteoporosis and osteoarthritis compared to those with GMFCS I-III (Table 2).
Moreover, a higher prevalence of musculoskeletal morbidity was found for individuals with GMFCS levels IV-V (59.3\%) as compared to those with GMFCS levels I-III (31.2\%), as well as higher odds of musculoskeletal morbidity (odds ratio [OR]: 3.41; 95\% CI: 2.18-5.35). Greater age (OR: 1.10; 95\% CI: 1.04-1.16) and underweight status (OR: 1.52; 95\% CI: 1.02-1.27) were both associated with musculoskeletal morbidity in individuals with CP.

\section{Cardiometabolic morbidity}

Adults with CP had a higher prevalence of hypertension, myocardial infarction, and hyperlipidemia compared to those without CP (Table 1). Adults with CP had a higher odds of cardiometabolic morbidity compared to those without $\mathrm{CP}$ (Table 3), and only obesity was significantly associated with cardiometabolic morbidity.

Of the adults with CP, those with GMFCS IV-V had a higher prevalence of hypertension and other cardiovascular problems compared to those with GMFCS I-III (Table 2). Moreover, a higher prevalence of cardiometabolic morbidity was found for individuals with GMFCS levels IV-V (26.2\%) compared to GMFCS levels I-III (15.2\%), as well as higher odds of cardiometabolic morbidity (OR: 2.05; 95\% CI: 1.20-3.50). Only obesity (OR: 1.85; 95\% CI: 1.01-3.41) was significantly associated with cardiometabolic morbidity in individuals with $\mathrm{CP}$.

\section{Pulmonary morbidity}

Adults with CP had a higher prevalence of asthma compared to those without CP (Table 1). There were no group differences in the odds of pulmonary morbidity (Table 3 ), and only smoking status was significantly associated with pulmonary morbidity.

Of the adults with CP, those with GMFCS IV-V had a higher prevalence of pulmonary embolism compared to those with GMFCS I-III (Table 2). No difference in prevalence of pulmonary morbidity was found for individuals with GMFCS levels IV-V compared to GMFCS levels I-III; however, individuals with GMFCS levels IV-V had higher odds of pulmonary morbidity (OR: 1.42; 95\% CI: $1.02-1.80)$.

\section{Multimorbidity}

Adults with CP had a higher prevalence of multimorbidity compared to those without CP (Table 1), as well as a higher odds of multimorbidity compared to those without CP (Table 4). Underweight, obesity, and smoking status were all significantly associated with multimorbidity. 


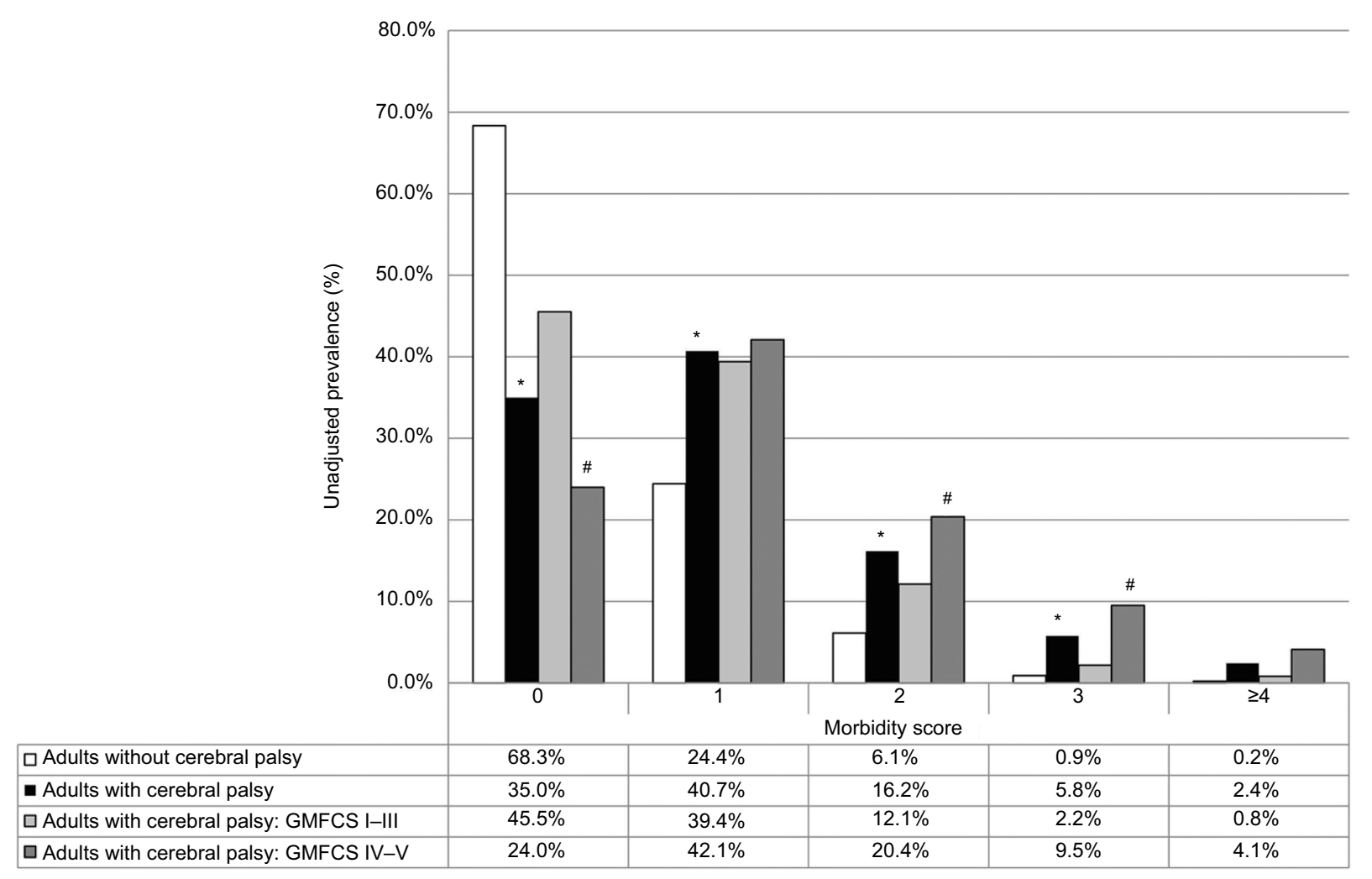

Figure I Prevalence of morbidity score for adults with CP vs without CP, as well as for adults with CP with GMFCS levels I-III vs IV-V.

Note: Significant differences between adults with and without CP $(*)$, and between GMFCS levels I-III vs IV-V $(\#) ; p<0.05$.

Abbreviations: CP, cerebral palsy; GMFCS, Gross Motor Function Classification System.

Of the adults with CP, adults with GMFCS IV-V had a higher prevalence of multimorbidity compared to those with GMFCS I-III (Table 2). There was also a higher odds of multimorbidity among those with GMFCS levels IV-V compared to GMFCS levels I-III (OR: 3.45; 95\% CI: 2.04-5.83). Only obesity (OR: 1.83; 95\% CI: 1.01-1.20) was significantly associated with multimorbidity in individuals with CP.

\section{Discussion}

The principal findings of this study are that young adults with CP have a higher prevalence of NCDs relating to musculoskeletal, cardiometabolic, and pulmonary systems compared to the general population of young adults without CP. Age, being underweight or obese, smoking, and the level of motor impairment were each independently associated with higher odds of many NCDs and multimorbidity in young adults with CP.

Over the past few decades, global disease burden has shifted from premature death to years lived with disabilities, and from communicable diseases to NCDs. ${ }^{13}$ Nearly $40 \%$ of global NCD-related deaths occur before the age of 70 years. ${ }^{26}$
Given the increased survival rate ${ }^{15}$ and a marginally increasing prevalence of $\mathrm{CP}^{16}$ throughout the past several decades, there is an expanding adult $\mathrm{CP}$ population that is at risk for premature NCD-related deaths. In the current study, young adults with CP had a higher prevalence of multiple NCDs and a multimorbidity prevalence of nearly $25 \%$. By middle age (40-60 years), adults with CP have a multimorbidity prevalence of nearly $60 \%,{ }^{19}$ which is $1.5-2.9$ times higher than the general population of middle-age adults. ${ }^{27}$ Collectively, these data highlight a CP-specific NCD burden that is unique from the general population.

\section{Musculoskeletal morbidity}

The finding that young adults with CP have a high prevalence of musculoskeletal morbidities is clinically important, but not surprising. Children with $\mathrm{CP}$ have an underdeveloped musculoskeletal system, ${ }^{5,6}$ with deficits presenting as early as 2 years old. ${ }^{28}$ Mobility deficits are observed as children with $\mathrm{CP}$ age into and throughout their adult years ${ }^{10-12}$ leading to a progressive loss of mechanical loading, which is an essential stimulus for musculoskeletal growth and maintenance. 
Table 3 Multiple logistic regression models for predictors of musculoskeletal, cardiometabolic, and pulmonary morbidities

\begin{tabular}{|c|c|c|c|c|c|}
\hline & Model predictor(s) & & Odds ratio & $95 \% \mathrm{Cl}$ & $p$-value \\
\hline \multirow[t]{10}{*}{ Musculoskeletal morbidity } & Cerebral palsy & Unadjusted & 10.10 & $6.77-15.1$ & $<0.001$ \\
\hline & & Adjusted & 6.97 & $4.46-10.89$ & $<0.001$ \\
\hline & Age (years) & & 1.09 & $1.03-1.14$ & $<0.001$ \\
\hline & Sex (Ref: women) & & 0.88 & $0.62-1.26$ & 0.48 \\
\hline & Race (Ref: Non-Hispanic White) & & 0.86 & $0.72-1.02$ & 0.08 \\
\hline & BMI category (Ref: normal weight [B & 24.9]) & & & \\
\hline & Underweight $(\mathrm{BMI}<18.5)$ & & 1.68 & $1.03-2.74$ & 0.04 \\
\hline & Overweight (BMI 25-29.9) & & 0.95 & $0.59-1.52$ & 0.82 \\
\hline & Obese $(\mathrm{BMI} \geq 30)$ & & 1.04 & $0.62-1.73$ & 0.89 \\
\hline & Smoking status (Ref: never smoked) & & 2.17 & $1.10-4.25$ & 0.03 \\
\hline \multirow[t]{10}{*}{ Cardiometabolic morbidity } & Cerebral palsy & Unadjusted & 2.84 & $1.89-4.26$ & $<0.001$ \\
\hline & & Adjusted & 1.98 & $1.26-3.13$ & $<0.01$ \\
\hline & Age (years) & & 1.05 & $0.99-1.11$ & 0.14 \\
\hline & Sex (Ref: women) & & I.II & $0.75-1.64$ & 0.61 \\
\hline & Race (Ref: Non-Hispanic White) & & 1.01 & $0.84-1.20$ & 0.96 \\
\hline & BMI category (Ref: normal weight [B & 24.9]) & & & \\
\hline & Underweight $(\mathrm{BMI}<18.5)$ & & 1.30 & $0.74-2.30$ & 0.37 \\
\hline & Overweight (BMI 25-29.9) & & 0.65 & $0.36-1.15$ & 0.13 \\
\hline & Obese $(\mathrm{BMI} \geq 30)$ & & 1.78 & $1.06-2.98$ & 0.02 \\
\hline & Smoking status (Ref: never smoked) & & 1.16 & $0.6 \mathrm{I}-2.22$ & 0.65 \\
\hline \multirow[t]{10}{*}{ Pulmonary morbidity } & Cerebral palsy & Unadjusted & 1.36 & $\mathrm{I} .0 \mathrm{I}-\mathrm{I} .84$ & 0.04 \\
\hline & & Adjusted & I.II & $0.78-1.58$ & 0.56 \\
\hline & Age (years) & & 0.97 & $0.92-1.02$ & 0.17 \\
\hline & Sex (Ref: women) & & 1.25 & $0.90-1.72$ & 0.18 \\
\hline & Race (Ref: Non-Hispanic White) & & 1.08 & $0.95-1.2$ & 0.22 \\
\hline & BMI category (Ref: normal weight $[B$ & 24.9]) & & & \\
\hline & Underweight $(\mathrm{BMI}<18.5)$ & & 1.15 & $0.69-1.93$ & 0.58 \\
\hline & Overweight (BMI 25-29.9) & & 1.06 & $0.7 I-I .59$ & 0.78 \\
\hline & Obese $(\mathrm{BMI} \geq 30)$ & & 1.26 & $0.79-2.00$ & 0.32 \\
\hline & Smoking status (Ref: never smoked) & & 1.42 & $1.02-1.97$ & 0.04 \\
\hline
\end{tabular}

Abbreviations: BMI, body mass index; Ref, reference.

Table 4 Multiple logistic regression models for independent predictors of multimorbidity

\begin{tabular}{|c|c|c|c|c|c|}
\hline & Model predictor(s) & & Odds ratio & $95 \% \mathrm{Cl}$ & $p$-value \\
\hline \multirow[t]{10}{*}{ Multimorbidity ${ }^{\mathrm{a}}$} & \multirow[t]{2}{*}{ Cerebral palsy } & Unadjusted & 4.12 & $2.7 I-6.26$ & $<0.001$ \\
\hline & & Adjusted & 2.67 & $1.69-4.23$ & $<0.001$ \\
\hline & \multicolumn{2}{|l|}{ Age (years) } & 1.00 & $0.94-1.05$ & 0.94 \\
\hline & \multicolumn{2}{|l|}{ Sex (Ref: women) } & 1.14 & $0.77-1.68$ & 0.51 \\
\hline & \multicolumn{2}{|l|}{ Race (Ref: Non-Hispanic White) } & 0.94 & $0.78-1.13$ & 0.50 \\
\hline & \multicolumn{5}{|c|}{ BMI category (Ref: normal weight [BMI I8.5-24.9]) } \\
\hline & \multicolumn{2}{|c|}{ Underweight $(\mathrm{BMI}<18.5)$} & 1.95 & $1.14-3.33$ & 0.01 \\
\hline & \multicolumn{2}{|l|}{ Overweight (BMI 25-29.9) } & 1.15 & $0.68-1.94$ & 0.61 \\
\hline & \multicolumn{2}{|l|}{ Obese $(\mathrm{BMI} \geq 30)$} & 2.04 & $1.20-3.47$ & 0.01 \\
\hline & \multicolumn{2}{|l|}{ Smoking status (Ref: never smoked) } & 1.92 & $\mathrm{I} .02-3.6 \mathrm{I}$ & 0.04 \\
\hline
\end{tabular}

Note: ${ }^{a} \geq 2$ musculoskeletal, cardiometabolic, and pulmonary morbidities.

Abbreviations: BMI, body mass index; Ref, reference. 
Mobility deficits are also associated with musculoskeletal pain, ${ }^{10,12}$ which is inversely related to physical activity levels in those with $\mathrm{CP}^{29} \mathrm{We}$ found age to be a significant risk factor for musculoskeletal morbidity in the current study, suggesting a worsening of musculoskeletal morbidity prevalence in those with $\mathrm{CP}$ even within a young and narrow age range.

\section{Cardiometabolic morbidity}

The progressive loss of function in persons with CP may help to explain why the risk for cardiometabolic morbidities is higher in young adults with $\mathrm{CP}^{30,31}$ The prevalence of hypertension and hyperlipidemia in young adults with $\mathrm{CP}$ in the current study was $11.8 \%$ and $3 \%$, respectively. Ryan et $\mathrm{al}^{32}$ showed that children and adolescents with CP, aged 6-17 years, had a $10.5 \%$ prevalence of hypertension, with age being significantly and positively associated with blood pressure. Moreover, van der Slot et $\mathrm{al}^{33}$ reported a higher prevalence of hypertension of $25.6 \%$ in those with $\mathrm{CP}$ between the ages of 25 and 45 years, while we have previously reported prevalences up to $50 \%$ in 40-60-year-olds for prehypertension and hypertension. ${ }^{19}$ Ryan et $\mathrm{al}^{34}$ found a prevalence of hyperlipidemia of $27.3 \%$ in adults with CP aged $18-65$ years, while $9 \%$ were taking medication for dyslipidemia and another $9 \%$ for hypertension. Although the frequency reporting myocardial infarction was low in the CP cohort (2\%) and absent in the adults without $\mathrm{CP}$ in the current study, the difference is still clinically meaningful given the young age of study participants. These findings suggest an early cardiovascular risk phenotype among individuals with $\mathrm{CP}$, which provides insight as to why adults with CP have a substantially higher cardiovascular mortality rates compared to the general population. ${ }^{17}$ Taken together, the window to prevent cardiovascular complications in those with CP occurs prior to reaching adulthood.

Somewhat surprisingly, we did not see a difference in the prevalence of impaired glucose tolerance or type 2 diabetes, which is consistent with another study in adults with CP that found normal fasting glucose levels. ${ }^{34}$ However, a glucose challenge, such as a glucose tolerance test, may be more indicative of glucose handling, and has not been exclusively studied in those with $\mathrm{CP}$. Elder et $\mathrm{l}^{35}$ reported that adults with spinal cord injury, a comparative reference population often used to better understand pathologies observed in $\mathrm{CP},{ }^{36,37}$ saw no differences in fasting glucose or insulin levels compared to individuals without CP. However, after administering a glucose load, both glucose and insulin levels were significantly elevated compared to individuals without $\mathrm{CP}$, suggesting impaired glucose handling. Given the hallmark altered musculoskeletal ${ }^{5,6,38}$ and functional profiles $^{5-7}$ in CP, both of which are associated with insulin resistance,,$^{30,31,35}$ it is curious as to why glucose dysregulation is not a prevalent complication in those with CP. This phenomenon requires further investigation; and yet, it may be a direct result of poor clinical screening for metabolic diseases in this population.

\section{Pulmonary morbidity}

Children with CP have poor cardiorespiratory fitness, which is associated with an increased cardiometabolic disease risk. ${ }^{8}$ In addition, the low cardiorespiratory capacity in children with $\mathrm{CP}^{39}$ is linked to lower chest mobility during respiration. ${ }^{40}$ It is of interest whether functional limitations in $\mathrm{CP}$ lead to pulmonary dysfunction and morbidity, or if pulmonary dysfunction and morbidity are drivers of the functional loss with age and subsequent increased risk for developing NCDs. Future research is needed to better understand the causal pathways leading to pulmonary dysfunction and morbidity in the context of disability severity.

The finding that modifiable risk factors, such as weight status and smoking status, are associated with NCDs and multimorbidity prevalence is consistent with our previous study in middle-age adults with CP. ${ }^{19}$ While there are known associations between NCDs and being underweight, ${ }^{41}$ being obese,${ }^{42}$ and using tobacco, ${ }^{14}$ there are weight management and smoking cessation programs that may help to mitigate the high prevalence of NCDs observed in the adult CP population. Not surprisingly, motor impairment was also significantly associated with NCDs and multimorbidity in the current study. In general, adults with CP have lower levels of physical activity. However, the degree of physical activity restriction is inversely related to increasing levels of motor impairment. ${ }^{43}$ Poor diet or malnutrition, tobacco use, and physical inactivity are the three most common modifiable risk factors associated with NCD-related premature death. ${ }^{14}$ These three modifiable risk factors are associated with NCDs and multimorbidity in the entire cohort of young adults with and without CP. Interestingly, young adults with CP had a fewer number of risk factors associated with musculoskeletal morbidity, pulmonary morbidity, and multimorbidity, but similar strength of associations, compared with the combined sample of young adults with and without CP. This may suggest that those with $\mathrm{CP}$ have a unique set of risk factors for developing or accelerating NCDs compared with the general population. Future initiatives are needed to develop programs with goals specific to assist persons with $\mathrm{CP}$ and caregivers for maintaining a healthy body composition, abstinence from tobacco use, and improving sleep, nutrition, and physical activity levels. ${ }^{44}$ 


\section{Strength and limitations}

The study has several strengths. To date, this is the largest study in young adults with $\mathrm{CP}$, which also includes a control group within the same age range. The recent initiatives in CP-specific surveillance programs have helped to identify a disease burden that is accelerated in the CP population by middle age. ${ }^{19}$ This has prompted the investigation of evaluating the NCD profiles in a younger cohort of adults with $\mathrm{CP}$ to help identify the window of disease clustering. Another strength of the current study is that all data were pulled from the same site (hospital system at the University of Michigan) and within a relatively narrow time period. This is important to consider because different global regions and time periods are associated with heterogeneous development of communicable diseases and NCDs. ${ }^{13}$

Several limitations must also be discussed. First, due to the design, we were unable to determine a cause and effect among exposures and outcomes. Second, we were limited to identifying NCDs using medical records that yielded a dichotomous coding for NCDs rather than a graded scale. Therefore, the severity of conditions was not accessible, which could have provided further insight into the NCD profiles of young adults with CP (eg, bone mineral density or T-scores for osteopenia and osteoporosis). Another limitation is the accuracy of the medical charts. If the NCD was not diagnosed on their medical chart, the participant was considered to not have that NCD. However, screening for NCDs in young adults with $\mathrm{CP}$ is not a common clinical practice in the United States. Therefore, our estimates may actually be underrepresenting the true extent of the NCD risk in young adults with CP.

\section{Conclusion}

Young adults with $\mathrm{CP}$ have a high prevalence of NCDs and multimorbidity, particularly for the musculoskeletal and cardiometabolic systems. Modifiable risk factors, such as underweight, obesity, and smoking status, were associated with NCDs and multimorbidity. This is an important finding because adults with $\mathrm{CP}$ are not expected to have such a disease burden at a young age, and clinical screening has been inadequate. Our findings highlight the importance of clinical screening for NCD clustering in persons with $\mathrm{CP}$ as early as adolescence or young adulthood, and may prompt early behavioral interventions for NCD prevention in this population.

\section{Acknowledgments}

We thank Rachael V Torres, University of Delaware, for critically reviewing the later versions of this manuscript. Mark D Peterson is funded by the National Institutes of Health (NIH) (1KO1 HD074706) and the National Institute on Disability,
Independent Living, and Rehabilitation Research (NIDILRR) (90IF0102-01).

\section{Author contributions}

EA Hurvitz and MD Peterson had full access to all of the data in the study and take full responsibility for the integrity of the data and the accuracy of the data analyses. DG Whitney, EA Hurvitz, JM Ryan, and MD Peterson contributed to the concept and design. EA Hurvitz, ZP French, EC Ellenberg, and MD Peterson contributed to acquisition of data. All authors contributed to drafting of the manuscript. MD Peterson contributed to statistical analysis, and study supervision. All authors contributed to the interpretation of data. EA Hurvitz, MJ Devlin, MS Caird, ZP French, EC Ellenberg, and MD Peterson contributed to administrative, technical, or material support. All authors contributed to critical revision of the manuscript for important intellectual content. All authors provided final approval of the manuscript version to be published, and have agreed to be accountable for all aspects of the work in ensuring that questions related to the accuracy or integrity of any part of the work are appropriately investigated and resolved.

\section{Disclosure}

The authors report no conflicts of interest in this work.

\section{References}

1. Christensen D, Van Naarden Braun K, Doernberg NS, et al. Prevalence of cerebral palsy, co-occurring autism spectrum disorders, and motor functioning - Autism and Developmental Disabilities Monitoring Network, USA, 2008. Dev Med Child Neurol. 2014;56(1):59-65.

2. Stackhouse SK, Binder-Macleod SA, Lee SC. Voluntary muscle activation, contractile properties, and fatigability in children with and without cerebral palsy. Muscle Nerve. 2005;31(5):594-601.

3. Moreau NG, Falvo MJ, Damiano DL. Rapid force generation is impaired in cerebral palsy and is related to decreased muscle size and functional mobility. Gait Posture. 2012;35(1):154-158.

4. Rose J, McGill KC. Neuromuscular activation and motor-unit firing characteristics in cerebral palsy. Dev Med Child Neurol. 2005;47(5): 329-336.

5. Whitney DG, Singh H, Miller F, et al. Cortical bone deficit and fat infiltration of bone marrow and skeletal muscle in ambulatory children with mild spastic cerebral palsy. Bone. 2017;94:90-97.

6. Johnson DL, Miller F, Subramanian P, Modlesky CM. Adipose tissue infiltration of skeletal muscle in children with cerebral palsy. J Pediatr. 2009;154(5):715-720.

7. Ryan JM, Forde C, Hussey JM, Gormley J. Comparison of patterns of physical activity and sedentary behavior between children with cerebral palsy and children with typical development. Phys Ther. 2015;95(12):1609-1616.

8. Ryan JM, Hensey O, McLoughlin B, Lyons A, Gormley J. Associations of sedentary behaviour, physical activity, blood pressure and anthropometric measures with cardiorespiratory fitness in children with cerebral palsy. PLoS One. 2015;10(4):e0123267.

9. Oftedal S, Davies PS, Boyd RN, et al. Body composition, diet, and physical activity: a longitudinal cohort study in preschoolers with cerebral palsy. Am J Clin Nutr. 2017;105(2):369-378. 
10. Morgan P, McGinley J. Gait function and decline in adults with cerebral palsy: a systematic review. Disabil Rehabil. 2014;36(1):1-9.

11. Day SM, Wu YW, Strauss DJ, Shavelle RM, Reynolds RJ. Change in ambulatory ability of adolescents and young adults with cerebral palsy. Dev Med Child Neurol. 2007;49(9):647-653.

12. Bottos M, Feliciangeli A, Sciuto L, Gericke C, Vianello A. Functional status of adults with cerebral palsy and implications for treatment of children. Dev Med Child Neurol. 2001;43(8):516-528.

13. Murray CJ, Vos T, Lozano R, et al. Disability-adjusted life years (DALYs) for 291 diseases and injuries in 21 regions, 1990-2010: a systematic analysis for the Global Burden of Disease Study 2010. Lancet. 2012;380(9859):2197-2223.

14. WHO. Global Action Plan for the Prevention and Control of Noncommunicable Diseases 2013-2020. Geneva, Switzerland: World Health Organization; 2013.

15. Brooks JC, Strauss DJ, Shavelle RM, Tran LM, Rosenbloom L, Wu YW. Recent trends in cerebral palsy survival. Part I: period and cohort effects. Dev Med Child Neurol. 2014;56(11):1059-1064.

16. Paneth N, Hong T, Korzeniewski S. The descriptive epidemiology of cerebral palsy. Clin Perinatol. 2006;33(2):251-267.

17. Strauss D, Cable W, Shavelle R. Causes of excess mortality in cerebral palsy. Dev Med Child Neurol. 1999;41(9):580-585.

18. Peterson MD, Ryan JM, Hurvitz EA, Mahmoudi E. Chronic conditions in adults with cerebral palsy. JAMA. 2015;314(21):2303-2305.

19. Cremer N, Hurvitz EA, Peterson MD. Multimorbidity in middle-aged adults with cerebral palsy. Am J Med. 2017;130(6):e9-744.e15.

20. Kruse M, Michelsen SI, Flachs EM, Bronnum-Hansen H, Madsen M, Uldall P. Lifetime costs of cerebral palsy. Dev Med Child Neurol. 2009;51(8):622-628.

21. Palisano RJ, Di Rezze B, Stewart D, et al. Life course health development of individuals with neurodevelopmental conditions. Dev Med Child Neurol. 2017;59(5):470-476.

22. Hanauer DA, Mei Q, Law J, Khanna R, Zheng K. Supporting information retrieval from electronic health records: a report of University of Michigan's nine-year experience in developing and using the Electronic Medical Record Search Engine (EMERSE). J Biomed Inform. 2015;55:290-300.

23. Quinones AR, Markwardt S, Botoseneanu A. Multimorbidity combinations and disability in older adults. J Gerontol A Biol Sci Med Sci. 2016;71(6):823-830.

24. Salive ME. Multimorbidity in older adults. Epidemiol Rev. 2013;35: 75-83.

25. James PA, Oparil S, Carter BL, et al. 2014 evidence-based guideline for the management of high blood pressure in adults: report from the panel members appointed to the Eighth Joint National Committee (JNC 8). JAMA. 2014;311(5):507-520.

26. WHO. Global Status Report on Noncommunicable Diseases 2014. Geneva, Switzerland: World Health Organization; 2014.

27. Rocca WA, Boyd CM, Grossardt BR, et al. Prevalence of multimorbidity in a geographically defined American population: patterns by age, sex, and race/ethnicity. Mayo Clin Proc. 2014;89(10):1336-1349.

28. Herskind A, Ritterband-Rosenbaum A, Willerslev-Olsen M, et al. Muscle growth is reduced in 15-month-old children with cerebral palsy. Dev Med Child Neurol. 2016;58(5):485-491.
29. Vogtle LK, Malone LA, Azuero A. Outcomes of an exercise program for pain and fatigue management in adults with cerebral palsy. Disabil Rehabil. 2014;36(10):818-825.

30. Luke A, Dugas LR, Durazo-Arvizu RA, Cao G, Cooper RS. Assessing physical activity and its relationship to cardiovascular risk factors: NHANES 2003-2006. BMC Public Health. 2011;11:387.

31. Camhi SM, Sisson SB, Johnson WD, Katzmarzyk PT, Tudor-Locke C. Accelerometer-determined moderate intensity lifestyle activity and cardiometabolic health. Prev Med. 2011;52(5):358-360.

32. Ryan JM, Hensey O, McLoughlin B, Lyons A, Gormley J. Reduced moderate-to-vigorous physical activity and increased sedentary behavior are associated with elevated blood pressure values in children with cerebral palsy. Phys Ther. 2014;94(8):1144-1153.

33. van der Slot WM, Roebroeck ME, Nieuwenhuijsen C, et al; MoveFit and Lifespan Research Group. Cardiovascular disease risk in adults with spastic bilateral cerebral palsy. J Rehabil Med. 2013;45(9):866-872.

34. Ryan JM, Crowley VE, Hensey O, McGahey A, Gormley J. Waist circumference provides an indication of numerous cardiometabolic risk factors in adults with cerebral palsy. Arch Phys Med Rehabil. 2014;95(8):1540-1546.

35. Elder CP, Apple DF, Bickel CS, Meyer RA, Dudley GA. Intramuscular fat and glucose tolerance after spinal cord injury--a cross-sectional study. Spinal Cord. 2004;42(12):711-716.

36. Bauman WA. The potential metabolic consequences of cerebral palsy: inferences from the general population and persons with spinal cord injury. Dev Med Child Neurol. 2009;51 (Suppl 4):64-78.

37. Peterson MD, Gordon PM, Hurvitz EA, Burant CF. Secondary muscle pathology and metabolic dysregulation in adults with cerebral palsy. Am J Physiol Endocrinol Metab. 2012;303(9):E1085-E1093.

38. Peterson MD, Gordon PM, Hurvitz EA. Chronic disease risk among adults with cerebral palsy: the role of premature sarcopoenia, obesity and sedentary behaviour. Obes Rev. 2013;14(2):171-182.

39. Gorter H, Holty L, Rameckers EE, Elvers HJ, Oostendorp RA. Changes in endurance and walking ability through functional physical training in children with cerebral palsy. Pediatr Phys Ther. Spring 2009;21(1):31-37.

40. Ersoz M, Selcuk B, Gunduz R, Kurtaran A, Akyuz M. Decreased chest mobility in children with spastic cerebral palsy. Turk J Pediatr. 2006;48(4):344-350.

41. Wang ZJ, Zhou YJ, Galper BZ, Gao F, Yeh RW, Mauri L. Association of body mass index with mortality and cardiovascular events for patients with coronary artery disease: a systematic review and meta-analysis. Heart. 2015;101(20):1631-1638.

42. Kearns K, Dee A, Fitzgerald AP, Doherty E, Perry IJ. Chronic disease burden associated with overweight and obesity in Ireland: the effects of a small BMI reduction at population level. BMC Public Health. 2014; 14:143.

43. Ryan JM, Crowley VE, Hensey O, Broderick JM, McGahey A, Gormley J. Habitual physical activity and cardiometabolic risk factors in adults with cerebral palsy. Res Dev Disabil. 2014;35(9):1995-2002.

44. Verschuren O, McPhee P, Rosenbaum P, Gorter JW. The formula for health and well-being in individuals with cerebral palsy: physical activity, sleep, and nutrition. Dev Med Child Neurol. 2016;58(9):989-990.
Clinical Epidemiology

\section{Publish your work in this journal}

Clinical Epidemiology is an international, peer-reviewed, open access, online journal focusing on disease and drug epidemiology, identification of risk factors and screening procedures to develop optimal preventative initiatives and programs. Specific topics include: diagnosis, prognosis, treatment, screening, prevention, risk factor modification,

Submit your manuscript here: https://www.dovepress.com/clinical-epidemiology-journal systematic reviews, risk and safety of medical interventions, epidemiology and biostatistical methods, and evaluation of guidelines, translational medicine, health policies and economic evaluations. The manuscript management system is completely online and includes a very quick and fair peer-review system, which is all easy to use. 